\title{
Ageing the European lobster Homarus gammarus by the lipofuscin in its eyestalk ganglia
}

\author{
M. R. J. Sheehy ${ }^{1, *}$, P. M. J. Shelton ${ }^{1}$, J. F. Wickins ${ }^{2}$, M. Belchier ${ }^{1}$, E. Gaten ${ }^{1}$ \\ ${ }^{1}$ Zoology Department, University of Leicester, University Road, Leicester LE1 7RH, United Kingdom \\ ${ }^{2}$ Ministry of Agriculture, Fisheries and Food, Fisheries Laboratory, Benarth Road, Conwy LL32 8UB, Wales, UK
}

\begin{abstract}
In this study, lipofuscin was examined in the eyestalk ganglia of tagged European lobsters Homarus gammarus released into the wild at Scapa Flow, Orkney, Scotland, at approximately 3 mo of age and recaptured at ages between 5.4 and 9.6 yr. Lipofuscin deposits were often most abundant in cell cluster $\mathrm{A}$ of the medulla terminalis (MT-A), where they exhibited typical autofluorescence, histochemical, distributional and structural properties. Confocal fluorescence microscopy and image analysis were used to quantify the deposits. The study demonstrated that lipof uscin accumulation in the MT$\mathrm{A}$ is age-dependent $(\mathrm{r}=0.640, \mathrm{p}=0.0002)$. For the available sample range, no other statistically significant relationships were found (carapace length vs age: $r=0.147, p=0.359$; body weight vs age: $r=-0.054, p=0.738$; carapace length vs lipofuscin concentration: $r=0.331, p=0.0849$; body weight vs lipofuscin concentration: $\mathrm{r}=0.181, \mathrm{p}=0.358$ ). Body size had no age discriminating power. There was no difference in lipofuscin accumulation rate between males and females. When placed in perspective against the highest lipofuscin concentrations so far measured for wild individuals of this species, it was apparent that the available sample of tagged lobsters, spanning an age interval of about 4 yr, represented only a very small window of the total lifespan. The results indicate that measurement of MT-A lipofuscin concentration will provide considerably more accurate age determination of fished lobsters than the current body-size-based approach. MT-A lipofuscin concentration correctly ages approximately $43 \%$ of lobsters in a sample to within 1 yr or less of their true age, and $95 \%$ of lobsters to within 3.5 yr. Carapace length correctly ages only $3 \%$ of individuals correctly to within 1 yr. The width of the $95 \%$ confidence intervals for carapace-length-based age estimates are so large as to render these estimates meaningless. Size-at-age and number-at-age data obtained using lipofuscin will prove useful for estimating growth and mortality in wild lobster populations and provide insight into potential biases in the current, conventionally derived estimates of these parameters. From a practical perspective, it is easier to sample nerve tissue containing lipofuscin from the eyestalk than the brain and has the advantage of leaving the lobsters in marketable condition.
\end{abstract}

KEY WORDS: Homarus gammarus - Lipofuscin - Age determination - Eyestalk ganglia · Fluorescence · Confocal - Tag-recapture

\section{INTRODUCTION}

A reliable method for age determination of the European lobster Homarus gammarus would provide a means to significantly complement knowledge of its population dynamics, life history and longevity, with the potential to enhance the management of the commercial fishery. Various techniques have been exam-

•E-mail: mrjs2@le.ac.uk ined in the past (see Sheehy \& Wickins 1994), including counts of the number of ommatidia in the compound eye (Shelton et al. 1981). These studies have, generally, not yielded satisfactory approaches to age determination. In the case of the eye, the number of facets is related to body size rather than age.

Several studies have demonstrated age-dependent lipofuscin accumulations in the neurones of decapods (Sheehy 1989, 1990a, Belchier et al. 1994, Sheehy et al. 1994, 1995a, de Kerros et al. 1995, Wahle et al. 1996). This work has focused on defining the relationship 
between age and lipofuscin accumulation in laboratory-or pond-cultured individuals of known age and also wild individuals of unknown age. No published information is available on lipofuscin accumulation in crustaceans of known age growing under natural conditions. For poikilotherms, natural temporal and spatial environmental variability may affect the physiological ageing processes which produce lipofuscin. The usefulness of lipofuscin as an age index under natural conditions needs to be tested, particularly for relatively long-lived species which comprise many commercially fished stocks.

So far, studies on lipofuscin in Crustacea have centred on the brain and, in particular, the olfactory lobe globuli cell masses (OLCM) where lipofuscin deposits are often particularly conspicuous. However, lipofuscin has also been observed in the eyestalk ganglia of crustaceans (Sheehy 1989), including those of Homarus gammarus (Sheehy \& Wickins 1994). If lipofuscin accumulation correlates with functionality or regionalizations of metabolic activity within tissues, it could be that patterns of accumulation in the eyestalk ganglia are quite different from those in the olfactory lobe of the brain. From a practical perspective, with a view to routine measurement of lipofuscin in individuals from commercial catches, use of the eyestalk ganglia rather than the brain would make sample collection easier and leave the lobsters in marketable condition.

From 1983 to 1988, tagged juvenile Homarus gammarus of known age were released at various sites around the coast of Britain as part of a major stock enhancement trial conducted by the Ministry of Agriculture, Fisheries and Food (MAFF), the Sea Fish Industry Authority (SFIA) and the North Western and North Wales Sea Fisheries Committee (NW\&NW SFC) (Anonymous 1995). Several hundreds of these lobsters were recaptured in subsequent years (Addison \& Bannister 1994, Bannister et al. 1994). This trial offered an outstanding opportunity to test lipofuscin as an index of lobster age under natural environmental conditions. With this objective in mind, brain and eyestalk ganglia samples from the recaptured lobsters were retained for lipofuscin analysis

In this paper, we examine lipofuscin in the eyestalk ganglia of Homarus gammarus and present some of the first results on its accumulation under natural conditions in lobsters of known age.

\section{MATERIALS AND METHODS}

Lobsters. Three types of Homarus gammarus samples were used for this study:

(1) Lobsters of known ages [1.9( $n=5), 4.2(n=5)$ and $4.7 \mathrm{yr}(\mathrm{n}=1))$, reared from hatching in seawater recir- culation systems, were obtained from the MAFF Fisheries Laboratory at Conwy, North Wales. The 1.9 and 4.2 yr old lobsters grew at ambient laboratory water temperatures of $15 \pm 3^{\circ} \mathrm{C}$ and the $4.7 \mathrm{yr}$ old individual at $17 \pm 5^{\circ} \mathrm{C}$. The culturing system and rearing conditions are comprehensively described elsewhere (Beard \& Wickins 1992)

(2) Micro-tagged lobsters ranging in age from approximately 5.4 to $9.6 \mathrm{yr}(\mathrm{n}=41)$, were recaptured between 1991 and 1994 from the SFIA's release site at Scapa Flow, Orkney, Scotland. These lobsters had been hatchery-reared for approximately 3 mo at ambient laboratory water temperatures of approximately $12.3 \pm 3^{\circ} \mathrm{C}$ prior to their release into the wild between 1984 and 1988. Average annual surface sea water temperature (SST) at Scapa Flow is about $8^{\circ} \mathrm{C}$. Details of hatchery rearing, tagging, release and recapture procedures can be found in Beard \& Wickins (1992), Burton (1993) and Addison \& Bannister (1994). Depending on pooling of batches prior to release and holding time after recapture, the ages of these lobsters were generally known to within 4 to 9 mo $(3.9$ to $10.8 \%$ of their true ages). Tissue samples from 28 of these lobsters were available for lipofuscin analysis.

(3) Eyestalk ganglia and brain samples from an unusually large, $166 \mathrm{~mm}$ orbital carapace length (CL), $4.09 \mathrm{~kg}$ live weight, male lobster caught near Plymouth, southwest England (avg sea surface temperature $\sim 11^{\circ} \mathrm{C}$ ), in September 1995 were available, as well as a brain sample from a $170 \mathrm{~mm}$ CL female caught at Kvitsøy, southwest Norway (avg SST $\sim 9^{\circ} \mathrm{C}$ ), in May 1995. Both of these lobsters were of unknown age.

Tissue collection and fixation. Experimental lobsters were sexed and weighed, and their orbital CL was measured. They were chilled prior to decapitation. Whole eyestalks were removed as close to their bases as possible and, for light microscopy, fixed immediately in $10 \%$ acetate-buffered formalin in seawater. For transmission electron microscopy, whole eyestalks were fixed in a solution of $4 \%$ paraformaldehyde $+5 \%$ glutaraldehyde in phosphate buffer Samples were stored in these fixatives pending further processing

Fluorescence microscopy. For fluorescence microscopy, the hard exoskeleton and cornea were dissected away from each fixed eye, leaving the internal musculature, connective tissue, retina and various eyestalk ganglia. This tissue mass was processed using standard histological procedures (Sheehy 1989, Sheehy \& Wickins 1994). It was dehydrated in ascending ethanol con centrations, cleared in xylene and embedded in wax. Embedded material was serially sectioned transversely at $6 \mu \mathrm{m}$. Sections were slide-mounted, dewaxed and covered with DPX under minimum thickness, no. 0 , coverslips (Chance Propper Ltd, Warley, UK). Lipofuscin in sections was detected by its characteristic yellow- 
orange autofluorescence on an Olympus BHS microscope with a BH2-RFL fluorescence attachment. The best intensity contrast to the background emission was achieved using green excitation at $545 \mathrm{~nm}$ and a barrier filter passing only orange-red emission above $590 \mathrm{~nm}$.

Histochemistry. The characteristic lipophilia of lipofuscin was confirmed by photographing the distribution of the fluorescent granules in uncovered sections. The same sections were then stained with Sudan Black

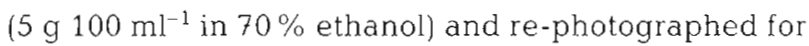
comparison (Sheehy 1989, Sheehy \& Wickins 1994).

Transmission electron microscopy. The medulla terminalis was isolated from the whole fixed eyestalk, washed in phosphate buffer and post-fixed overnight in $1 \%$ osmium tetroxide in phosphate buffer. It was then washed in distilled water, dehydrated in ascending concentrations of acetone and embedded in Spurr's resin. Ultra-thin sections $(0.1 \mu \mathrm{m})$ were cut using a diamond knife on a Huxley ultramicrotome and floated onto 200 mesh copper grids. Sections were stained in aqueous uranyl acetate and Reynold's lead citrate using standard procedures. They were observed on a Jeol CX100 transmission electron microscope.

Lipofuscin distribution. The 3-dimensional internal structure of the eyestalk ganglia was mapped using a complete series of Mallory's triple stained longitudinal sections from an adult lobster and reconstructed with MacStereology software, version 2.8 (Ranfurly Microsystems, Oxford, UK). The presence of lipofuscin in the various eyestalk ganglia was then determined using fluorescence microscopy of comparable unstained series of sections.

Lipofuscin quantification. Subclusters of globuli cells in soma cluster A (after Blaustein et al. 1988) of the medulla terminalis (MT-A) (Fig. 1) were selected for lipofuscin quantification since these consistently had the most prominent lipofuscin deposits. This region was serially sectioned transversely and all sections containing the large fibre tract connection to the hemiellipsoid body (hemiellipsoid bundle) were used $(n=15$ to 54 ). In each section, an image of the area containing the largest aggregations of lipofuscin was recorded. Areas containing large neurosecretory cells or spaces, or that were damaged, were not used. Lipofuscin was detected and measured using an Axiovert 10 inverted epifluorescence microscope (Carl Zeiss Ltd, Welwyn Garden City, UK) equipped with a Lasersharp MRC 600 confocal laser scanning system and COMOS version 7 software (Bio-Rad Laboratories Ltd, Hemel Hempstead, UK). Sections were excited at $514 \mathrm{~nm}$ and emission above $550 \mathrm{~nm}$ was detected through a $63 \times$ oil immersion objective. For consistency with previous studies, the laser scan window was zoomed by a factor of 1.6 to give an effective objective magnification of $100 \times$. Adequate digital image quality was achieved by using neutral density filter no. 2 with the confocal aperture wide open. The gain was set at maximum, with Kalman averaging of 5 image scans to remove noise. Images were monochrome with 255 grey levels. Brightly fluorescing lipofuscin granules were readily discriminated from the darker background of cell bodies using manual greyscale thresholding provided by the software. The area fraction of lipofuscin in each image, as a percentage, was determined by dividing the cross-sectional area of lipofuscin granules by the total background area of cell bodies in the image, and multiplying by 100 . The average area fraction of all sections examined for each individual was calculated. In line with stereological convention, this average was recorded as, and equivalent to, the volume fraction, in percent (\% VF), of lipofuscin in the region of the MT-A under examination.

Statistical analysis. Confidence intervals for age estimates based on MT-A lipofuscin concentration or carapace length were calculated according to the regression method described by Sokal \& Rohlf (1981, p 498) for inverse predictions. Confidence intervals were used as an indicator of potential error in the age estimate. The probability level of confidence intervals for individual age estimates is the probability that the true age of the individual falls within the calculated limits. The $95 \%$ confidence band for age predictions, for example, encompasses $95 \%$ of the sample observations around the regression of the predictor on age. The probability level, therefore, also gives an indication of the proportion of individuals in a sample which will be correctly aged at the corresponding level of confidence or error. For comparison, the relationships between probability level (proportion of individuals in the sample) and width of confidence interval (potential age prediction error or resolution) for age estimates based on carapace length and MT-A lipofuscin were determined from the Scapa Flow data.

\section{RESULTS}

Lipofuscin granules were associated with globuli and neurosecretory cell bodies in most soma clusters of the eyestalk ganglia of older lobsters. In the oldest individuals, where lipofuscin deposits were particularly dense, the granules were also found in neuropile regions (Fig. 1). Granules were typically spherical but irregular in outline, with diameters usually less than $5 \mu \mathrm{m}$ but sometimes in excess of $10 \mu \mathrm{m}$ in older specimens. With green excitation and a $590 \mathrm{~nm}$ barrier filter, lipofuscin emission appeared bright red against a darker background of cell bodies (white granules in Fig. 2a). It was extraction-resistant and stained positively for lipids with Sudan Black (Fig. 2b), but there 


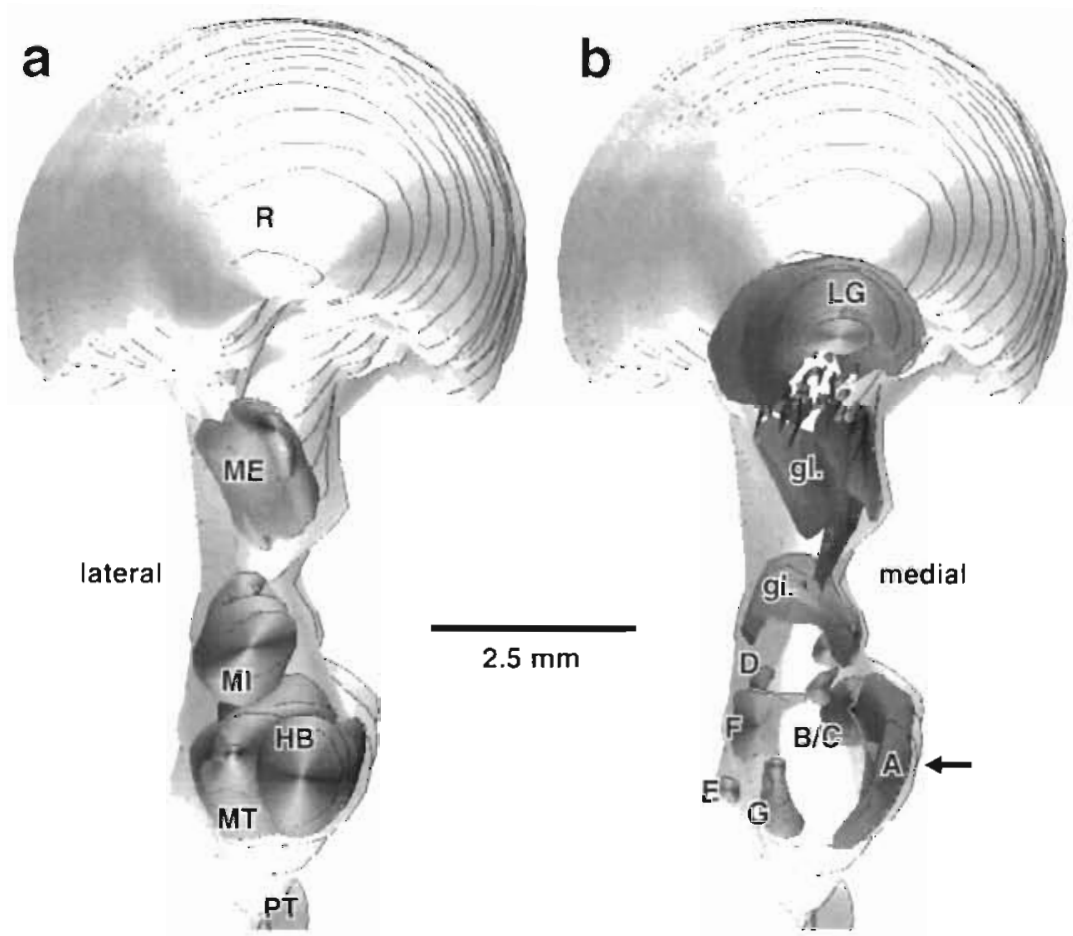

Fig. 1. Homarus gammarus. Features of the nervous system in the left eyestalk (dorsal view, 3D serial-section reconstruction). (a) Location of neuropiles: ME, medulla externa; MI, medulla interna; MT, medulla terminalis; HB, hemiellipsoid body; also: $\mathrm{R}$, retina; $\mathrm{PT}$, protocerebral tract. (b) Distribution of main groups of cell somata: $A-G$, cell clusters of the medulla terminalis (after Blaustein et al. 1988); LG, lamina ganglionaris; gl., small globuli cells. Arrow is parallel with plane of sectioning of cell cluster A where lipofuscin was quantified was heterogeneity both within and between granules in affinity for the stain (Fig. 3a). At an ultrastructural level, the granules were completely or partially membrane bound, often very irregular in appearance and contained masses of membrane fragments, multilamellar whorls, more homogeneous electron dense areas and sometimes vacuoles (Fig. 3b). They sometimes comprised an overwhelming proportion of the cytoplasmic volume. The granule depicted in Fig. 3b was located in an out-pouching of the cell membrane in close proximity to the nucleus. The granules were also located in nerve fibres and sometimes appeared to be extraneuronal.

Lipofuscin deposits were generally less obvious in the lamina ganglionaris and small globuli cell clusters of the external and internal medullae and were more prominent in the cell clusters of the medulla terminalis. They were often particularly dense in the MIT-A, although subclusters in this region clearly had differential accumulation rates. For instance, the cellular region in the lower right of Fig. 2a, b had much fewer lipofuscin deposits than the rest of the cell mass.

The median concentration of lipofuscin in the MT-A of the $1.9 \mathrm{yr}$ old laboratory-reared lobsters, $0.066 \% \mathrm{VF}$, was significantly different from, and lower than, that of comparable $4.2 \mathrm{ys}$ old individuals, $0.66 \%$ VF ( $p=$ 0.0079, $n=10$, Mann-Whitney Rank Sum Test) (Fig. 4). Average lipofuscin accumulation in these lobsters, over the 2.3 yr interval separating them, was $0.26 \% \mathrm{VF} \mathrm{yr}^{-1}$.
Table 1 presents a statistical summary of the relationships depicted in Figs. 5 \& 6 . No statistically significant relationships $(p>0.05)$ existed between carapace length or body weight and MT-A lipofuscin concentrations in the sampled lobsters (Fig. 5a, b).

Lipofuscin concentration in the MT-A of the lobsters from Scapa Flow increased in a significant linear fashion with age $(p=0.0002, r=0.64)$, over the time interval studied (Fig. 6a). Lipofuscin accumulation rate in these lobsters averaged $0.070 \% \mathrm{VF} \mathrm{yr}^{-1}$. There were no significant differences $(\mathrm{p}>0.05)$ in amounts or rates of accumulation of lipofuscin between sexes, as indicated by the similarity in regression slopes, elevations and $95 \%$ confidence limits. Prediction bands encompassing $95 \%$ of the data points were relatively broad. Downward extrapolation of the trend line suggested that, under the prevailing environmental conditions, resolvable lipofuscin accumulation in the MT-A first appeared at an age of about $2.7 \mathrm{yr}$ No statistically significant relationships ( $p>0.05$ ) between carapace length or body weight and age, or sexual differences in these variables, were detected in the sampled lobsters (Fig. 6c,e).

In Fig. 6b, the lipofuscin data from the Scapa Flow sample are placed in perspective against the highest lipofuscin concentrations so far observed in this laboratory for wild Homarus gammarus. Whilst both the MT$A$ and the OLCM of the large male Plymouth lobster contained comparable lipofuscin concentrations of 


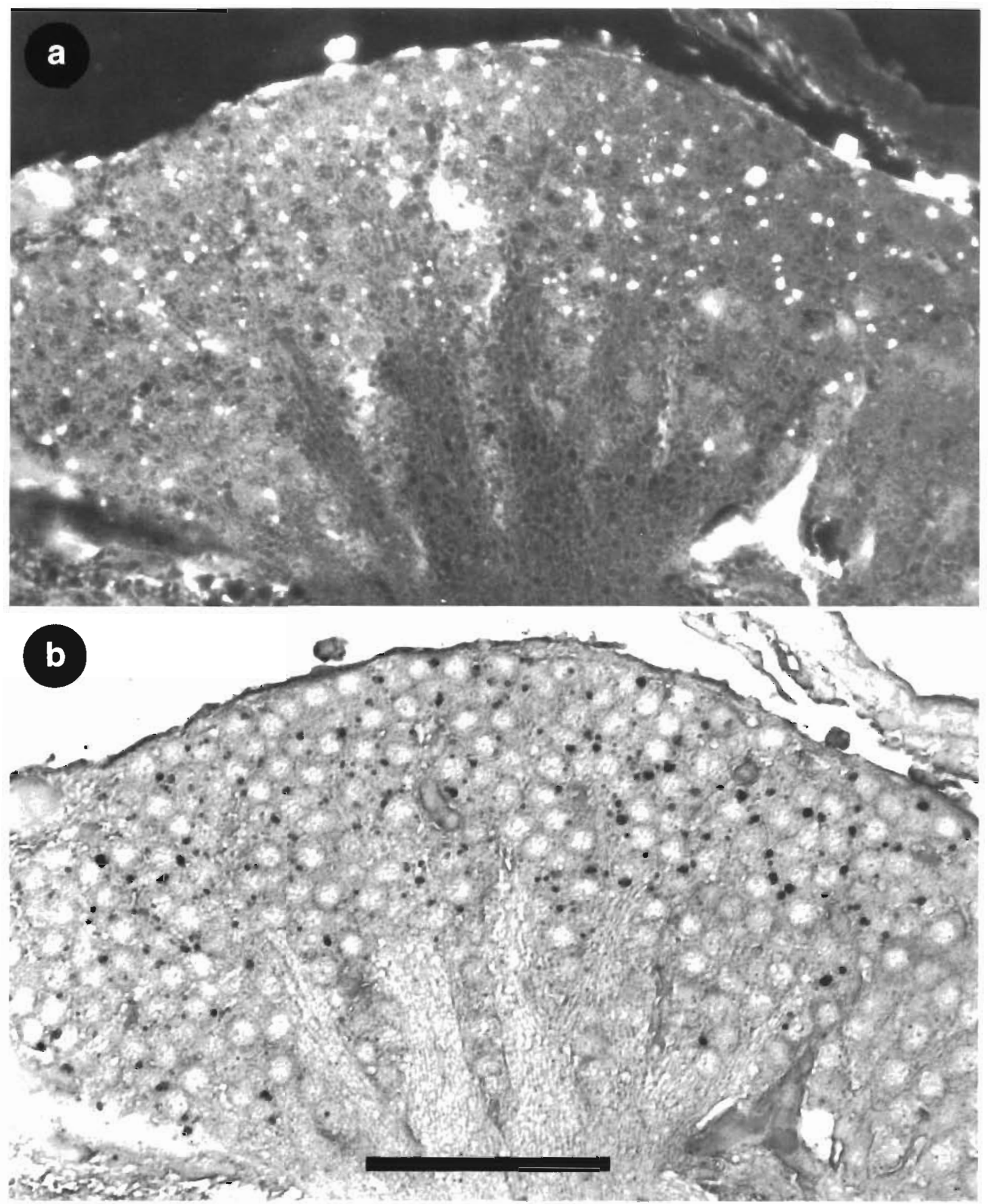

Fig. 2. Homarus gammarus. Lipofuscin associated with globuli cells in cluster A of the medulla terminalis in a 4.7 yr old lobster laboratory-reared at $17 \pm 5^{\circ} \mathrm{C}(6 \mu \mathrm{m}$ wax section). (a) Red fluorescent emission of the granules (appearing white here) under green excitation. (b) Identical distribution of Sudan B stained granules under bright-field illumination. The distribution of lipofuscin granules is not even, with fewer present in the lower right part of the field. Scale bar $=100 \mu \mathrm{m}$ 


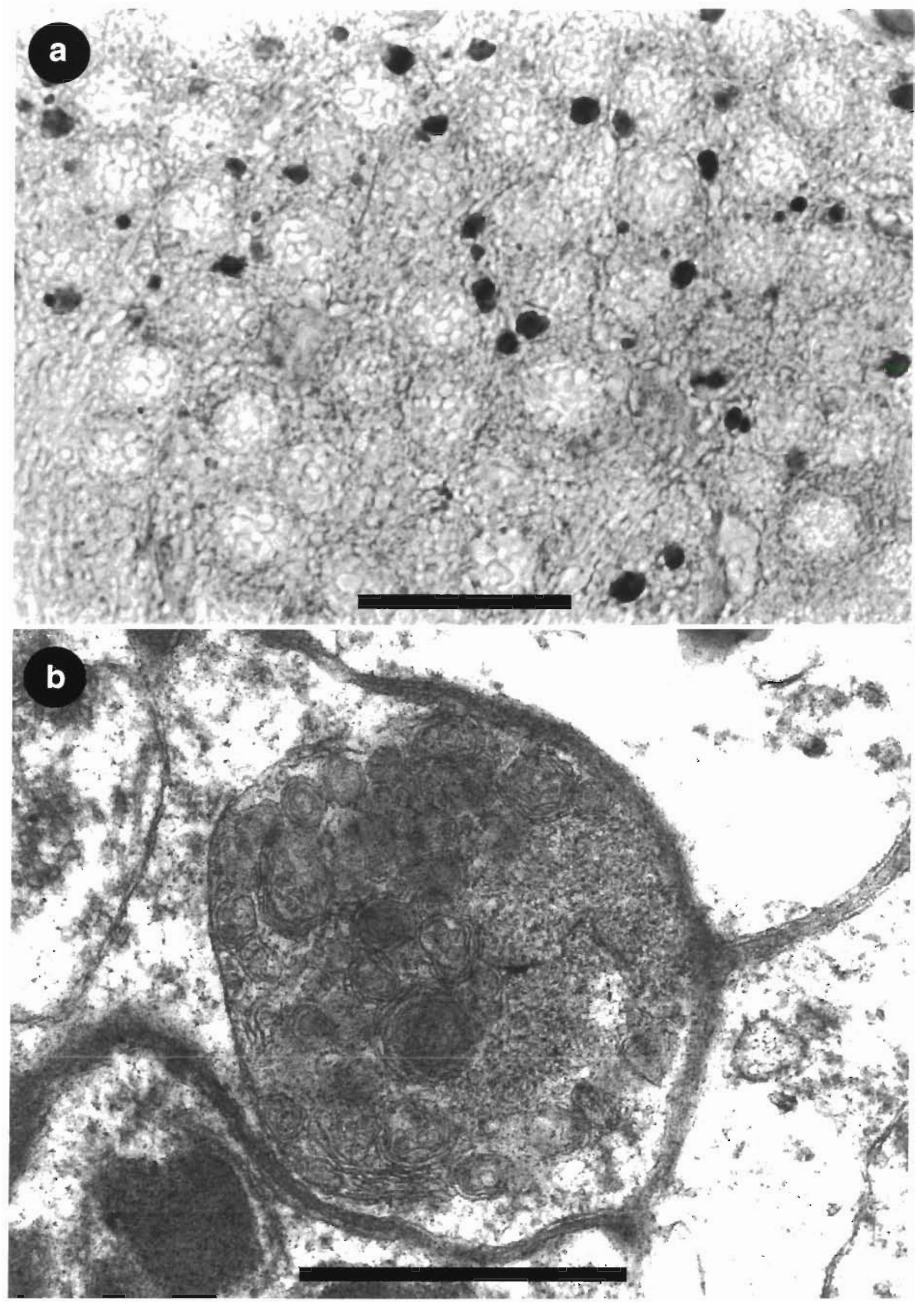

Fig. 3. Homarus gammarus. (a) Higher magnification of area in Fig. 2 showing irregular morphology of lipofuscin granules. Scale bar $=30 \mu \mathrm{m}$. (b) Transmission electron micrograph showing a typical membrane bound lipofuscin granule containing dense material and membrane whorls. Scale bar $=1 \mu \mathrm{m}$ 


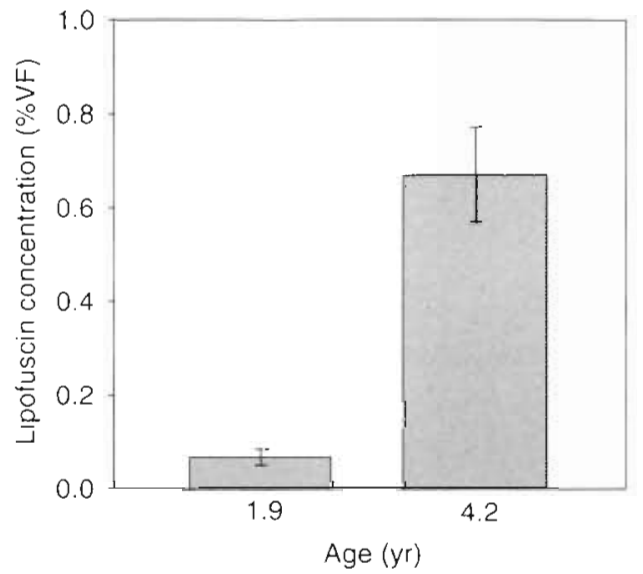

Fig. 4. Homarus gammarus. Mean concentrations and their $95 \%$ confidence intervals for lipofuscin in cell cluster A of the medulla terminalis in lobsters of 2 known ages, 1.9 and 4.2 yr, laboratory-reared at $15 \pm 3^{\circ} \mathrm{C}$

only about $1 \% \mathrm{VF}$, the OLCM of the slightly larger female from Kvitsøy contained $3.9 \%$ VF of lipofuscin. In Fig. 6d, the Scapa Flow size-at-age data were superimposed on growth curves for Orkney lobsters obtained using conventional methods ( $\mathrm{J}$. Kinnear pers. comm.). The weight-converted forms of these growth curves are shown in Fig. 6f. In each case, it is clear that the available sample represents only a very small window in the lifespan.

Based on the data from Scapa Flow, Fig. 7 depicts potential age estimation error against the corresponding proportion of individuals in a sample which will be aged with that level of error or better. Using MT-A. lipofuscin concentration, $43 \%$ of individuals will be correctly aged to within 1 yr or less, and $95 \%$ to within $3.5 \mathrm{yr}$. On the other hand, using carapace length, only about $3 \%$ of individuals will be aged correctly to within $1 \mathrm{yr}$ and the $95 \%$ confidence intervals for age estimates are so wide ( $82 \mathrm{yr}$ ) as to render these estimates meaningless.
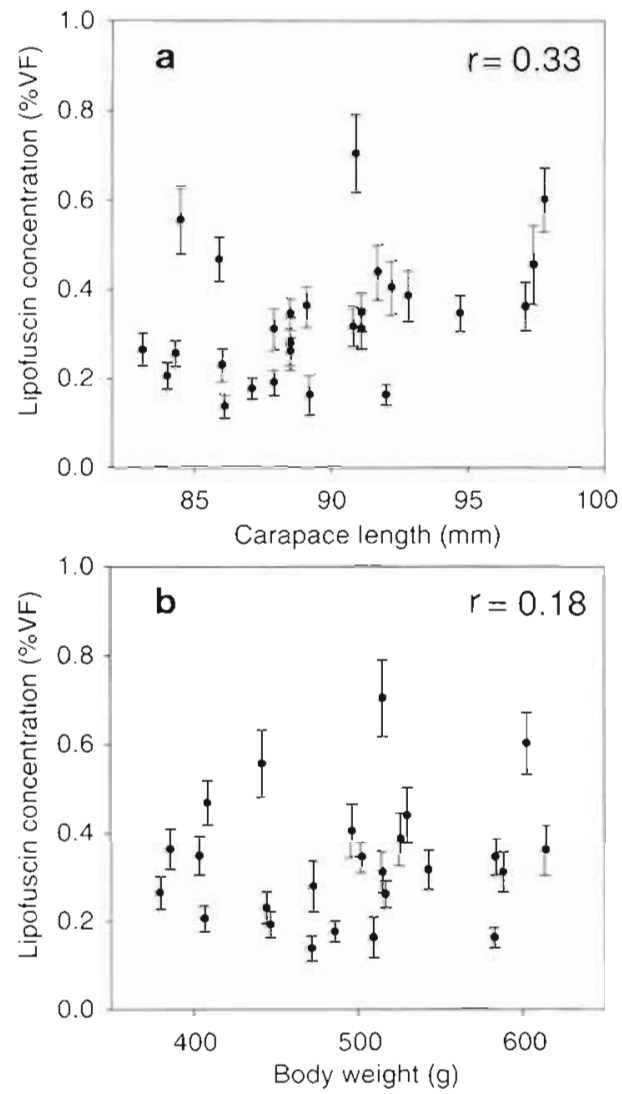

Fig. 5. Homarus gammarus. Mean lipofuscin concentrations and their $95 \%$ confidence limits for Scapa Flow lobsters plotted against (a) carapace length and (b) weight

\section{DISCUSSION}

A sizeable volume of literature on the microanatomy and histochemistry of decapod eyestalk ganglia contains little reference to lipofuscin. This may be because crustacean lipofuscin is not particularly obvious under microscopic bright-field illumination using stains designed to reveal general anatomical detail (Sheehy

Table 1. Summary of regression statistics for the relationships plotted in Figs. 5 \& 6 between lipofuscin concentration in cell cluster A of the medulla terminalis, age, carapace length and body weight for tagged lobsters recaptured at Scapa Flow, Orkney, Scotland: $x$, independent variable; $y$, dependent variable; $n$, sample size; a, regression constant; $b$, regression slope; $r$, correlation coefficient; $p$ probability of being wrong in concluding that there is a true association between the variables, '.'statistical significance

\begin{tabular}{|c|c|c|c|c|c|c|}
\hline$x$ & $y$ & $\mathrm{n}$ & a & $b$ & $r$ & $\mathrm{p}$ \\
\hline Age $(y r)$ & Lipofuscin conc. (\% VF) & 28 & -0.1890 & 0.0698 & 0.64 & $0.0002 \cdots$ \\
\hline Age (yr) & Carapace length $(\mathrm{mm})$ & 41 & 85.04 & 0.721 & 0.15 & 0.3591 \\
\hline Age $(y r)$ & Body weight (g) & 41 & 558.4 & -6.37 & -0.05 & 0.7376 \\
\hline Carapace length (mm) & Lipofuscin conc. ( $\%$ VF) & 28 & -0.6114 & 0.0105 & 0.33 & 0.0849 \\
\hline Body weight (g) & Lipofuscin conc. (\% VF) & 28 & 0.2020 & 0.000266 & 0.18 & 0.3579 \\
\hline
\end{tabular}



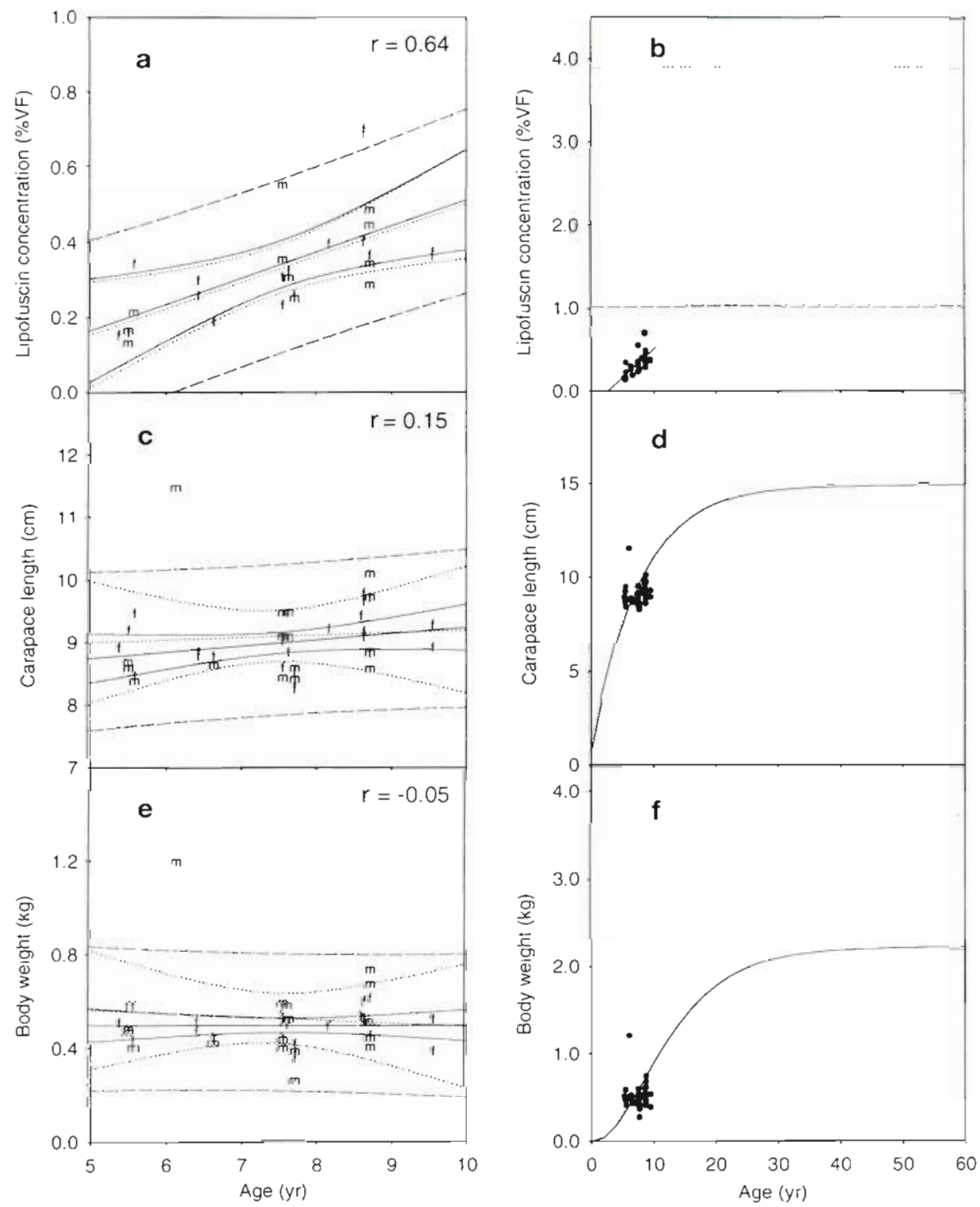

Fig. 6. Homarus gammarus. Relationships between lipofuscin concentration in cell cluster A of the medulla terminalis, age, carapace length and body weight for tagged lobsters recaptured at Scapa Flow. Graphs (a), (c) and (e) are scaled to incorporate data ranges from Scapa Flow samples only. Regressions (-) and their $95 \%$ confidence limits (...) for females, $\mathrm{f}$, and males, $\mathrm{m}$, respectively. (--) $95 \%$ prediction lines for the whole sample. Pearson correlation coefficients, $r$ are also shown. Data are placed in context in (b), (d) and (f), where graphs are scaled to incorporate upper data ranges estimated from this and other studies. (b) Lipofuscin concentration (--) measured in both cell cluster $A$ of the medulla terminalis and the olfactory lobe cell mass of a $166 \mathrm{~mm} \mathrm{CL}$ male from Plymouth, UK; maximum lipofuscin concentration $(\cdots .$.$) so$ far encountered in a wild lobster, from the olfactory lobe cell mass of a $170 \mathrm{~mm} \mathrm{CL}$ female from Kvitsøy, Norway. (d) Growth curves for male (…) and female (-) H. gammarus from Orkney obtained using conventional methods (J. Kinnear pers. comm.). (f) Weight-converted forms of these growth curves
1989). On the other hand, when viewing sections for fluorescence, it may be that lipofuscin autofluorescence is so ubiquitous that it confounds the detection of, or is confused with, the specific induced-fluorescences under examination (Vandelest et al. 1995). This study on Homarus gammarus is the first to directly examine lipofuscin age pigment in the eyestalks of a crustacean and confirms previous preliminary observations on the eyestalk ganglia of this species (Sheehy \& Wickins 1994) and the freshwater crayfish. Cherax cuspidatus (Sheehy 1989).

The autofluorescence, histochemical, distributional and structural properties, as well as the age-related accumulation of lipofuscin in the MT-A of Homarus gammarus were similar to those described for lipofus- cin in its OLCM (Sheehy \& Wickins 1994) and those of other species (Sheehy 1989, 1990a, b, Belchier et al. 1994, Sheehy et al. 1994, 1995a, de Kerros et al. 1995 , Wahle et al. 1996).

In the neurones of the eyestalk ganglia of Homarus gammarus, lipofuscin granules range in size and internal morphology from small, fairly round and homogeneous, lysosome-like structures up to very large, fully or partially membrane-bound, irregular conglomerates filling most of the perinuclear cytoplasm and displacing or deforming other cellular structures. These ultrastructures seem consistent with the idea that during the normal process of autolytic recycling of old or worn out cellular components certain 'lysosomotropic' agents (de Duve et al. 1974, Eldred \& Lasky 1993) 


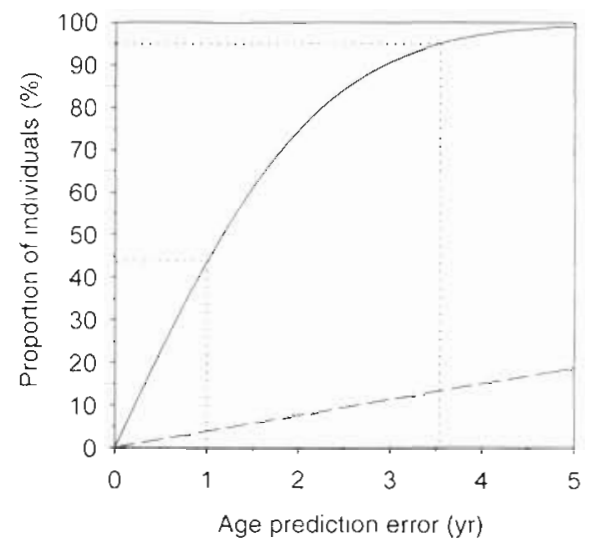

Fig. 7 Relationship between potential age prediction error (confidence interval for age estimates) and the corresponding proportion of individuals in a sample which will be aged correctly to within that level of error, based on the results from Scapa Flow depicted in Fig. 6. Relationships for lipofuscinbased (-) and carapace-length-based (--) age predictions are shown

become lodged and, over time, clog the lysosomes, rupturing their membranes and spilling digestive enzymes into the cytoplasm. This may be followed eventually by cell death, for which the presence of extracellular granules may be evidence. Alternatively, some mechanism of granule expulsion may exist. More detailed ultrastructural studies of lipofuscin in crustaceans are required to determine how well a taxonomically distant invertebrate model fits the present, largely vertebrate-based concepts of age pigment formation and cellular turnover. However, observations to date suggest a pattern of morphogenesis similar to that described for vertebrate lipofuscins.

As in the brain, there are clear regionalizations of lipofuscin deposition in the eyestalk ganglia, both within and between cell clusters. From work on vertebrates, it has been proposed that tissue regions with higher lipofuscin loads represent more metabolically active sites (Friede 1962, Ferrendelli et al. 1971), or are less well protected by enzymes against free radical damage (Pisanti et al. 1983). It may be significant that the MT-A is connected to neuropiles which are in turn linked through the olfactory globular tracts to the olfactory lobe (Blaustein et al. 1988). These 2 sites in the eye and the brain, respectively, show relatively high rates of lipofuscin accumulation. Future studies on metabolism, characterization of antioxidant systems and lipid biochemistry in the crustacean nervous system, in relation to age and lipofuscin accumulation, should provide useful insight into these distribution patterns.

Along with concurrent studies on the brain in our laboratory, this is the first examination of lipofuscin accumulation in marine crustaceans of known age growing under natural conditions. Previous research on freshwater crayfish Cherax quadricarinatus reared under both constant laboratory and variable field conditions, yielded correlations with age in excess of 0.9 . The correlation between age and MT-A lipofuscin concentration for the tagged Scapa Flow lobsters in the present study $(0.64)$, therefore, seemed relatively low. Initially, this result appeared to confirm that environmental heterogeneity in the field had had an impact on within-age-group variation in lipofuscin concentration. However, the importance of placing available data in context relative to the whole lifespan of the species under examination has been noted earlier (Sheehy 1990C, 1992).

Present indications are that there is little difference in the average accumulation rate of lipofuscin in tagged, known-age lobsters recaptured at various landing sites around Britain and that the individual's MT-A and OLCM lipofuscin concentrations are roughly comparable (M. Belchier unpubl, data). A lipofuscin concentration of $3.9 \% \mathrm{VF}$ in the OLCM of an unusually large Norwegian specimen of Homarus gammarus of unknown age approached the highest average levels that have been measured so far in any crustacean (Sheehy et al. 1995b). From this perspective, it is apparent that the available sample of tagged lobsters, ranging in age from about 5.4 to $9.6 \mathrm{yr}$, represents only a very small window in a total lifespan measured in decades. Such a conclusion on the lobsters' longevity would be consistent with both anecdotal evidence and extrapolations from growth studies (e.g. Fig. 6d, f) (Wolff 1978). However, a much more extensive data-set on lipofuscin accumulation is needed before firmer estimates of longevity can be made. If a similarly restricted range of ages, relative to the whole lifespan, had been examined in studies of Cherax quadricarinatus, correlation coefficients would have been comparably lowered. When viewed against the maximum lipofuscin levels attainable, the relative within-age-group variation in lipofuscin concentration in the MT-A of $H$. gammarus from Scapa Flow did not differ much from that in either field- or laboratoryreared $C$. quadricarinatus (compare Fig. $6 \mathrm{~b}$ with Figs. 1B \& 3A of Sheehy et al. 1994).

Often, variations in lipofuscin accumulation rates in comparable tissues from different species have been interpreted in the context of Pearl's (1928) 'rate of living' theory (Miquel et al, 1976. Sohal \& Donato 1978, 1979, Sohal 1981, McArthur \& Sohal 1982, Sheehy et al. 1995b). Species with longer lifespans tend to have lower basal metabolic rates and, biologically, age more slowly. An alternative concept is that longer-lived species may have more effective or enduring homeostatic mechanisms for the repair or prevention of most sto- 
chastic degradative processes (Holliday 1995). Such processes include lipofuscin formation. Results of the present study are consistent with these concepts. In the field, lipofuscin accumulation rate in the MT-A of Homarus gammarus $\left(0.07 \%\right.$ VF $\left.\mathrm{yr}^{-1}\right)$ was about 27 times lower than that in the OLCM of Cherax quadricarinatus (1.87\% VF yr ${ }^{-1}$, Sheehy et al. 1994). Also, the initial 2 mo period of negligible lipofuscin accumulation in juvenile C. quadricarinatus (Sheehy 1990a, Sheehy et al. 1994) seemed to correspond to a period of about 2.7 yr for H. gammarus from Scapa Flow.

Another cause for the observed differences may be the effect of differing environmental temperatures on rate of ageing and lipofuscin formation (Sheehy et al. 1995b). Homarus gammarus from Scapa Flow experience much colder water temperatures (avg $\sim 8^{\circ} \mathrm{C}$ ) than Cherax quadricarinatus from sub-tropical Brisbane (avg $-22^{\circ} \mathrm{C}$ ). The relatively high average lipofuscin accumulation rate $(0.26 \% \mathrm{VF})$ in lobster reared in the laboratory at Conwy may also be the result of the higher water temperatures there (avg $-15^{\circ} \mathrm{C}$ ) compared with Scapa Flow.

It is clear from the present data that relatively large variations in size-at-age in Homarus gammarus are not confined to laboratory rearing systems (Wickins \& Beard 1991), but also exist in the wild. The very poor correlations of carapace length or weight with age observed for Scapa Flow lobsters, over the age range examined, were consistent with those reported by Bannister et al. (1994) for H. gammarus on the English east coast, as well as Cherax quadricarinatus and other crustaceans (Sheehy 1990a 1992, Sheehy et al. 1994). Based on size alone, any lobster in the Scapa Flow sample could have come from any year class within the sample range. Size had no age discriminating power within the age range examined. However, it should be pointed out that the size-at-age regressions presented here cannot be interpreted as segments of the complete growth curve because of the very limited age range of the data and size-biases in the catch. For instance, the negative slope of the relationship between weight and age is clearly artefactual. The data appear to suggest an asymptote at about $90 \mathrm{~mm}$ $\mathrm{CL}$ between 5 and $10 \mathrm{yr}$ of age. However, it is extremely unlikely that this is the true average maximum potential size $\left(L_{\text {rxax }}\right)$ given that 2 very much larger individuals ( 166 and $170 \mathrm{~mm} \mathrm{CL}$ ) were obtained for the study and the largest individual $H$. gammarus so far recorded had a carapace length in excess of $250 \mathrm{~mm}$ (Wolff 1978). Rather, continuing fishing pressure will have removed almost all older, larger individuals from the population.

The presence of a conspicuous outlier at 6 yr of age in Fig. 6c, e was evidence of the fact that some individuals have unusually high growth rates. Unfortunately, a lipofuscin sample from this individual was not available. The relatively low lipofuscin concentration detected in the brain of the $166 \mathrm{~mm}$ CL. Plymouth lobster suggested that it was not particularly old. On the other hand, the $170 \mathrm{~mm}$ CL Kvitsøy lobster was probably very old, based on its relatively high lipofuscin loading. This is consistent with the idea that unusually large individuals, which approach the asymptotic size, may be either relatively young and fast growing or relatively old and slow growing. Average water temperatures at Plymouth are warmer than at Kvitsøy by only about $2^{\circ} \mathrm{C}$. Therefore, there is no evidence to suggest that the markedly higher lipofuscin concentration in the Kvitsøy lobster is a temperature effect. On the other hand, the much greater apparent age of the large female is as expected if the growth rate of mature females is lower than males (Wolff 1978).

Alterations in eye weight have provided indices for age determination in many species (Friend 1967). In ageing mammals, the focal capacity and opacity of the lens decline with gradual crosslinkage and other chemical alterations of the long-lived crystalin proteins of which it is comprised. These changes are 2 of the best biomarkers of human aging (Holliday 1995); biochemical measurement of lens protein crosslinkage has been used for accurate age determination of mice, for example (Dapson \& Irland 1972). In certain myriapods and insects, the number of eye facets increases at ecdysis and is, therefore, reported to provide a general indication of moult stage or age (Shelton 1976. Southwood 1978).

Although sought after, a means for ageing crustaceans from their eyes has, until now, proved elusive. Faceting of the crustacean compound eye has been shown to relate to body size rather than to age (Shelton et al. 1981: Homarus gammarus; Meyer-Rochow et al. 1990: Petrolisthes elongatus). In Euphausia superba, the number of eye facets does not appear to diminish during the over-winter period of starvation and body shrinkage, thereby eliminating a source of variance which otherwise confounds attempts to use body size for age estimation in this species (Sun et al. 1995). Nevertheless, we are still left with the question of how closely the number of eye facets really relates to age. Again for the purpose of age determination, Crossland et al. (1988) attempted to measure lipofuscin in eye tissue from the western rock lobster Panulirus cygnus and scampi Metanephrops andamanicus using the then-accepted biochemical assay procedure. They concluded that FAP (fluorescent age pigment) did not provide the resolution needed. However, the measurement technique employed in that study is now considered to be unreliable (Sheehy 1996)

Thus, the results of the present study show, for the first time, a feature of the crustacean eye whose alter- 
ation is truly related to ageing rather than growth. The relatively stronger correlation of lipofuscin concentration with age than with body size was as expected from previous studies on Cherax quadricarinatus over a wide range of thermal conditions (Sheehy 1990a, 1992, Sheehy et al. 1994, 1995b). Lipofuscin accumulation in the neurones seems quite independent of whole body metabolism. Rather, it may be better interpreted in terms of the physiology of specific tissue regions or individual cells (Sheehy et al. 1995b). No sexual difference in lipofuscin accumulation rate has been shown in Homarus gammarus or the Cherax species so far examined (Sheehy 1990a, c, Sheehy et al. 1995b)

The level of resolution with which age classes can be determined using lipofuscin depends upon the relationship between rate of lipofuscin accumulation and the variation in its concentration within age groups. It was suggested that the absolute resolution of a lipofuscin age index would be higher in short-lived species than in long-lived ones because of the expected slower accumulation rate in the latter (Sheehy 1992). From the present study on the relatively long-lived Homarus gammarus, this appears to have proved correct. The age of individual Cherax quadricarinatus can be accurately resolved to within a few months using their OLCM lipofuscin concentration. The present data show that the age of individual $H$. gammarus is only resolved with $95 \%$ confidence to within about $3.5 \mathrm{yr}$, however about $43 \%$ of individuals in a sample are correctly aged to within $1 \mathrm{yr}$ or better. Discrimination of year class modes in lipofuscin concentration frequency histograms from large population samples remains to be tested.

Use of eyestalk rather than brain for lipofuscin quantification will make sample collection easier and, uniquely, may not necessarily require sacrifice of the individual involved, potentially allowing a second sequential cellular measurement of lipofuscin concentration. This may circumvent selective-mortalityinduced biases which can arise from the usual practice of determining rates of biological ageing and lipofuscin accumulation from population averages (Donato et al. 1979 a, b). Such an approach could also prove useful for determining lipofuscin accumulation rates in tagged recaptured lobsters from the wild, particularly where the pre-release ages of the lobsters are unknown (Crossland et al. 1988).

The size range of individuals used in the present study encompasses the vast majority of legal-sized lobsters landed by fisheries around Britain (Hepper 1978, Howard 1980, Bannister et al. 1983, 1994). At first glance, the lack of a relationship between the sizes of lobsters and their ages seems to contradict conventionally-determined growth curves and much empirical data on the growth of wild-caught lobsters. In reality, the broad relationship between size and age that must exist in growing lobsters will be obscured because the size and age range of individuals used in this study, and normally taken by the fisheries, is very narrow compared with variation in size-at-age and relative to the maximum attainable size and age. Fished lobsters are currently assigned to a specific year class depending on the particular $5 \mathrm{~mm}$ CL interval into which they fall. The present results suggest that this approach correctly ages only an extremely small proportion of the catch to the level of year class. Age estimates using lipofuscin should prove extremely useful for fisheries management. A classification based on $0.07 \%$ VF lipofuscin concentration intervals, for example, would age many lobsters more accurately. Through improved size-at-age and number-at-age data, valuable insight into potential biases in the current, conventionally derived models for lobster growth and mortality should be attainable, with the potential for enhanced management.

Further studies are now needed, particularly on the age structure of the wild lobster stocks, using the available lipofuscin data as a reference. Also, while microscopy and image analysis of histological sections remains the most reliable method for measurement of lipofuscin concentration (Sheehy 1996), in the routine analysis of large fisheries samples, exploration for faster alternatives should be promoted.

Acknowledgements. Project funding (CSA 2596) from MAFF UK is gratefully acknowledged. Colin Bannister (MAFF Directorate of Fisheries Research, Lowestoft, England) and Colin Chapman (SOAFD Marine Laboratory, Aberdeen, Scotland) have provided valuable advice and assistance on the project since its inception. Data on the Scapa Flow releaserecapture program and growth of Scottish lobsters were kindly provided by Craig Burton (SFIA, Marine Farming Unit, Ardtoe, Scotland) and Jim Kinnear and Nick Bailey (SOAFD Marine Laboratory, Aberdeen, Scotland). Thanks also to Steve Renfree (District Fisheries Office, Plymouth Fisheries, England) and Ingebrigt Uglem (Institute of Marine Research, Bergen, Norway) for arranging the supply of large lobsters from Plymouth and Kvitsøy, respectively, and to Tony Child (MAFF Fisheries Laboratory, Conwy, North Wales) for critically reading the manuscript.

\section{LITERATURE CITED}

Addison JT, Bannister RCA (1994) Re-stocking and enhancement of clawed lobster stocks: a review. Crustaceana $67(2): 131-155$

Anonymous (1995) Lobster stocking: progress and potential. Significant results from the UK restocking studies, 1982 to 1995. MAFF Directorate of Fisheries Research, Lowestoft, UK

Bannister RCA, Addison JT, Lovewell SRJ (1983) Results of a recent minimum size assessment for the fisheries for lobster, Homarus gammarus, in England and Wales. ICES CM 1983/K:4 
Bannıster RCA, Addison JT, Lovewell SRJ (1994) Growth, movement, recapture rate and survival of hatchery-reared lobsters (Homarus gammarus (Linnaeus, 1758)) released into the wild on the English east coast. Crustaceana 67(2): $156-172$

Beard TW, Wickins JF (1992) Techniques for the production of juvenile lobsters (Homarus gammarus). MAFF Directorate of Fisheries Research, Lowestoft, UK, Fisheries Research Tech Rep no. 92

Belchier M, Shelton PMJ, Chapman CJ (1994) The identification and measurement of fluorescent age-pigment abundance in the brain of a crustacean (Nephrops norvegicus) by confocal microscopy. Comp Biochem Physiol 108B(2): $157-164$

Blaustein DN, Derby CD, Simmons RB, Beall AC (1988) Structure of the brain and medulla terminalis of the spiny lobster Panulirus argus and the crayfish Procambarus clarkii, with an emphasis on olfactory centers. J Crustacean Biol 8(4):493-519

Burton CA (1993) The United Kingdom lobster stock enhancement trials. In: Braine MPS (ed) Proceedings of the 1.st British conference on artificial reefs and restocking. September 12, 1992. Stromness, Orkney, p 22-35 (mimeo)

Crossland CJ, Denby G, Phillips BF, Brown R (1988) The use of fluorescent pigments (lipofuscin) for ageing western rock lobster (Panulirus cygnus) and scampi (Metanephrops andamanicus): a preliminary assessment. CSIRO Marine Laboratories, Australia, Rep no. 195

Dapson RW, Irland JM (1972) An accurate method of determining age in small mammals. J Mammal 53(1):100-106

de Duve $C$, de Barsy $T$, Poole $B$, Trouet $A$, Tulkens $P$, Van Hoof F (1974) Lysosomotropic agents. Biochem Pharmacol 23:2495-2531

de Kerros A, Conan G, Sheehy MRJ (1995) Age determination of Homarus americanus using an index of lipofuscin abundance. ICES CM 1995/K:39

Donato H, Hoselton MA, Sohal RS (1979a) An analysis of the effects of individual variation and selective mortality on population averages. Exp Gerontol 14:133-140

Donato H, Hoselton MA, Sohal RS (1979b) Lipofuscin accumulation: effects of individual variation and selective mortality on population averages. Exp Gerontol 14:141-147

Eldred GE, Lasky MR (1993) Retinal age pigments generated by self-assembling lysosomotropic detergents. Nature $361: 724-726$

Ferrendelli JA, Sedgwick WG, Suntzeff $V$ (1971) Regional energy metabolism and lipofuscin accumulation in mouse brain during ageing. J Neuropath \& Exp Neur 30:638-649

Friede RL (1962) The relation of formation of lipofuscin to the distribution of oxidative enzymes in the human brain. Acta Neuropathol 2:113-125

Friend $M$ (1967) A review of research concerning eve-lens wexght as a criterion of age in animals. NY Fish Game J 14 $152-165$

Hepper BT (1978) Population dynamics of the lobster Homarus gammarus (L.) off the coasts of England. MAFF Directorate of Fisheries Research, Lowestoft, UK. Fisheries Research Tech Rep no. 41

Holliday R (1995) Understandıng ageing. Cambridge University Press, Cambridge

Howard AE (1980) Substrate controls on the size composition of lobster (Homarus gammarus) populations. I Cons Int Explor Mer 39:130-133

McArthur MC, Sohal RS (1982) Relationsh.p between metabolkc rate, aging, lipid peroxidation, and fluorescent age pigment in the milkweed bug. Oncopeltus fasciatus
(Hemiptera). J Gerontol 37:268-274

Meyer-Rochow VB, Towers D, Ziedins I (1990) Growth pat terns in the eye of Petrolisthes elongatus (Crustacea Decapoda; Anomura). Exp Biol 48:329-340

Miquel J, Lundgren PR, Bensch $\mathrm{KG}_{1}$, Atlan $\mathrm{H}(1976)$ Effects of temperature on the life span, vitality and fine structure of Drosophila melanogaster. Mech Ageing Dev 5:347-370

Pearl R (1928) Experiments on longevity. Q Rev Biol 3 $391-407$

Pisanti FA, Frascatore S, Aloj Totaro E, Vuttariello E (1983) Superoxide dismutase in the central nervous system of Torpedo marmorata. Arch Gerontol Gicriatr 2:34.3-347

Sheehy MRJ (1989) Crustacean brain lipofuscin: an examination of the morphological pigment in the freshwater crayfish Cherax cuspidatus. J Crustacean Biol 9:387-391

Sheehy MRJ (1990a) The potential of morphological lipofuscin age-pigment as an index of crustacean age. Mar Biol $107: 439-442$

Sheehy MRJ (1990b) The widespread occurrence of fluorescent morphological lipofuscin in the crustacean brain. $J$ Crustacean Biol 10:613-622

Sheehy MRJ (1990c) Individual variation in, and the effect of rearing temperature and body size on, the concentration of fluorescent morphological lipofuscin in the brains of freshwater crayfish Cherax cuspidatus. Comp Biochem Physiol 96A:281-286

Sheehy MRJ (1992) Lipofuscin age-pigment accumulation in the brains of ageing field-and laboratory-reared crayfish Cherax quadricarinatus (von Martens) (Decapoda: Parastacidae). J Exp Mar Biol Ecol 161:79-89

Sheehy MRJ (1996) Quantitative comparison of in situlipofuscin concentration with soluble autofluorescence intensity in the crustacean brain. Exp Gerontol 31(3):421-432

Sheehy MRJ, Cameron E, Marsden G, McGrath J (1995a) Age structure of female giant tiger prawns Penaeus monodon as indicated by neuronal jipofuscin concentration. Mar Ecol Prog Ser 117:59-63

Sheehy MRJ, Greenwood JG, Fielder DF (1994) More accurate chronological age determination of crustaceans from the field using the physiological age marker, lipofuscin. Mar Biol 121:237-245

Sheehy MRJ, Greenwood JG, Fielder DR (1995b) Lipofuscin as a record of rate of living in an aquatic poikilotherm. $J$ Gerontol: Biol Sci 50A:B327-B336

Sheehy MRJ, Wickins, JF (1994) Lipofuscin age pigment in the brain of the European lobster, Homarus gammarus (L.). Microsc Anal 40:23-25

Shelton PMJ (1976) The development of the insect compound eye. In: Lawrence P (ed) Insect development. Symposium of the Royal Entomological Society 8. Blackwell Scientific Publications, London, p 152-169

Shelton PMJ, Shelton RGJ, Richards PR (1981) Eye development in relation to moult stage in the European lobster Homarus gammarus (L.). J Cons Int Explor Mer 39:239-243

Sohal RS (1981) Metabolic rate, ageing, and lipofuscin accumulation. In: Sohal RS (ed) Age Pigments. Elsevier/NorthHolland Biomedical Press, Amsterdam p 303-316

Sohal RS, Donato H (1978) Effects of experimental prolongation of lifespans on the accumulation of fluorescent age pigment in the housefly Musca domestica. Exp Gerontol 13:335-341

Sohal RS, Donato H (1979) Effect of experimental prolongation of lifespan on lipofuscin content and lysosomal enzyme activity in the brain of the housefly Musca domes. tica. J Gerontol 34:489-496

Sokal. RR, Rohlf FJ (1981) Biometry. WH Freeman \& Co, San Francisco 
Southwood TRE (1978) Ecological methods. Chapman \& Hall. London

Sun S, de la Mare W, Nicol S (1995) The compound eye as an indicator of age and shrinkage in Antarctic krill. Antarct Sci 7(4):387-392

Vandelest CHA, Versteeg EMM, Veerkamp JH, Vankuppevelt TH (1995) Elimination of autofluorescence in immunofluorescence microscopy with digital imageprocessing. 3 Histochem Cytochem 43(7):727-730

This article was submitted to the editor
Wahle RA, Tully O, O'Donovan $V$ (1996) Lipofuscin as an indicator of age in crustaceans: analysis of the pigment in the American lobster Homarus americanus. Mar Ecol Prog Ser 138:117-123

Wickins JF, Beard TW (1991) Vanability in size at moult among individual broods of cultured juvenile lobsters, Homarus gammarus (L.). Aquacult Fish Manage 22:481-489

Wolff $T$ (1978) Maximum size of lobsters (Homarus) (Decapoda, Nephropidae). Crustaceana 34(1):1-14

Manuscript first received: June 7, 1996

Revised version accepted: September 3, 1996 